\title{
Correspondence
}

\section{CHECKLIST FOR DIAGNOSIS OF BRAIN DEATH}

\section{To the Editor:}

Although the revised Canadian guidelines for the determination of brain death were published in the Journal ${ }^{1}$ and the Canadian Medical Association Journal,2 their application in the intensive care units (ICUs) should not be taken for granted. Charts often leave doubt that the recommended tests have been performed, that they have been carried out properly and that all the criteria are satisfied.

For several months we have been using a checklist (see right) in the ICU of Victoria Hospital. The check list, which addresses all the essential aspects of the Canadian guidelines, is completed at the bedside and left on the patient's chart. A policy statement, which contains the details of the 1987 guidelines, is also kept in the ICU for reference when completing the checklist. This has been well received. A similar checklist has been developed in Britain. ${ }^{3}$

We strongly endorse the development of similar checklists for all ICUs in Canada; we encourage neurologists to take the initiative in developing these. Such a development will assure application of the Canadian guidelines and better documentation that they have been properly applied in the declaration of brain death for legal and transplant purposes.

Explanations:

1. $\mathrm{TcpO}_{2}$ and $\mathrm{TcpCO}_{2}$ refer to transcutaneous partial pressures of oxygen and carbon dioxide, respectively for those patients with transcutaneous measuring devices.

2. Physicians A and B are the two physicians who independently assess the patient. These individuals should not have a conflict of interest involving the decision to use organs for transplantation.

G.B. Young

T. Frewen

H.W.K. Barr

G.G. Hinton

W.T. Blume

J.B. Kronick

C.F. Bolton

F. Rutledge

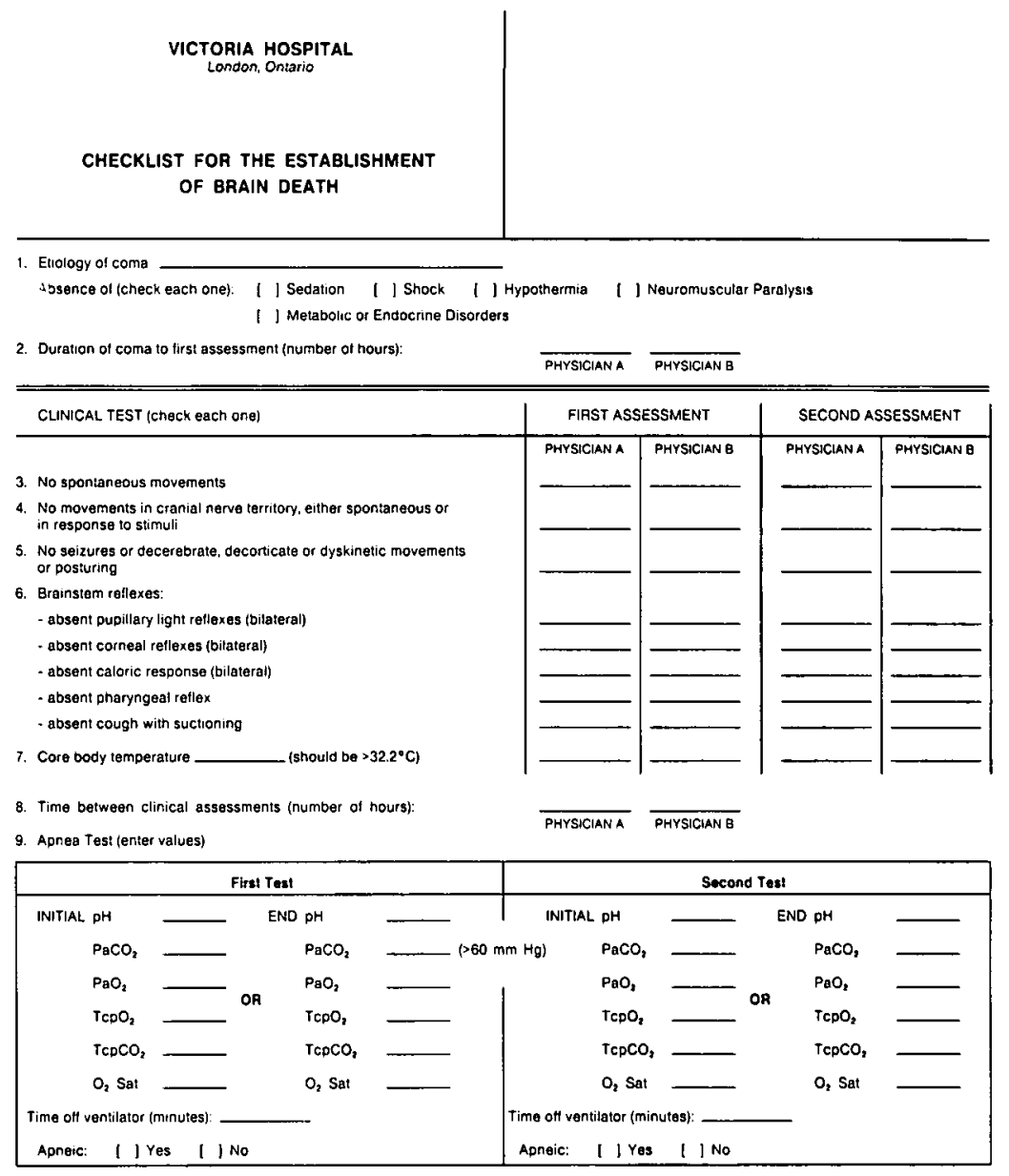

10. Contirmatory test, it required. Specity test and resutt.

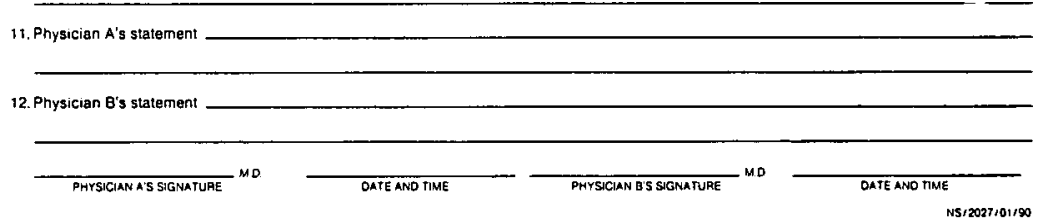

1. Committee on Brain Death. Guidelines for the diagnosis of brain death. Can J Neurol Sci 1986; 13: 355-358 and 1987; 14: 653-656.

2. Committee on Brain Death. Guidelines for the diagnosis of brain death. Can Med Assoc J 1987; 136: 200A-200B.

3. O'Brien MD. Criteria for diagnosing brain stem death. Br Med J 1990; 310: 108109. 